\title{
Intra-Thyroidal Thymic Tissue May Display Radiological Features Suggestive of Malignancy - A Case Report
}

\author{
Rebecca Harrison*, Laura Warner and Sean Loughran \\ Department of Paediatric Otolaryngology, Royal Manchester Children's Hospital, Central Manchester University Hospitals NHS Foundation Trust \& \\ Manchester Academic Health Science Centre, UK
}

Submission: July 13, 2018; Published: August 01, 2018

*Corresponding author: Rebecca Harrison, Royal Manchester Children's Hospital, Oxford Road, Manchester, M139WL, Fax: 01617017903; Tel: 01617015039; Email: rebecca.harrison19@nhs.net

\begin{abstract}
Introduction: Thyroid "incidentalomas" are increasing in frequency, thought mainly to be a result of the enhanced sensitivity of ultrasonography and the increasing use of this imaging technique. We present two cases of thyroid nodules in paediatric patients which were found to be intrathyroidal thymic tissue.

Case report: The first case displayed ultrasonographic features that were highly suspicious for papillary thyroid cancer with microcalcification, however following diagnostic hemithyroidectomy the lesion was diagnosed as intra-thyroidal ectopic thymic tissue. Histologically, calcified Hassall's corpuscles would account for the calcified appearance of the nodule on ultrasound scan. We describe a further case of intra-thyroidal ectopic thymic tissue in another paediatric patient who presented with a thyroid mass.
\end{abstract}

Discussion: It is important to consider thymic remnant tissue as a differential diagnosis for incidental thyroid nodules.

Keywords: Paediatric; Otolaryngology; Incidental finding; Endocrine gland neoplasms; Thyroid malignancy

\section{Introduction}

Thyroid nodules are less commonly found in children, affecting $0.2-1.5 \%$, when compared to adult patients [1]. Paediatric thyroid lesions are however more likely to be malignant and must be carefully investigated $[1,2]$. There are sporadic reports of intra-thyroidal thymic tissue in the literature, however increasing ultrasound scan use and enhanced sensitivity of ultrasonographic images has resulted in a rise in incidentally found thyroid lesions, which is likely to increase further $[3,4]$. This has created a diagnostic dilemma for clinicians and lead to an increase in diagnostic thyroid surgeries and an increase in detection of microcarcinomas. Thymic tissue has a distinctive appearance on ultrasound with features that may be misinterpreted as a malignant thyroid nodule [3].

We report two cases of intra-thyroidal ectopic thymic tissue in paediatric patients, both presenting with a thyroid mass. One patient displayed radiological features that were suspicious of malignancy. Both patients underwent diagnostic hemithyroidectomy.

\section{Case Report}

\section{Case 1}

A 4-year-old girl with no co-morbidities presented with cervical lymphadenopathy following an upper respiratory tract infection. An ultrasound noted cervical lymphadenopathy and a solitary thyroid nodule with appearances suspicious of papillary thyroid cancer. There was no family history or other risk factors for thyroid malignancy. Blood tests revealed normal thyroid function, calcitonin and thyroid auto-antibodies.

A repeat ultrasound scan of the neck revealed a hypo-echoic nodule within the left lobe of the thyroid, displaying microcalcification and was taller than wide leading to a U5 (malignant) diagnostic ultrasound grading (Figure 1). Following diagnostic hemi-thyroidectomy, the nodule was histologically found to be ectopic thymic tissue within the thyroid lobe, with calcification of Hassall's corpuscles, which would account for the calcified appearance on ultrasound scan. 


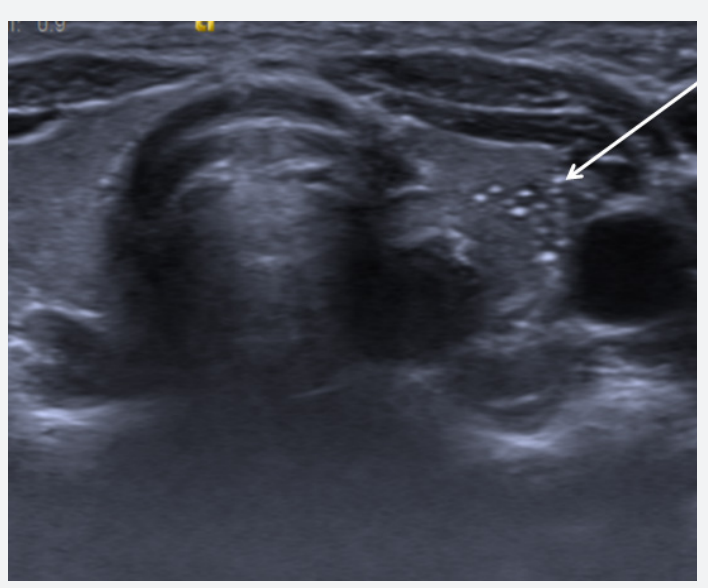

Figure 1: Intra-thyroidal thymic tissue with appearances of papillary thyroid cancer. Micro-calcifications were later found to be calcified Hassall's corpuscles (arrow).

\section{Case 2}

A 12-year-old boy with no co-morbidities presented with a midline neck swelling that had appeared 6 weeks previously. Clinically he was found to have a $4.0 \times 5.0 \mathrm{~cm}$, non-tender neck mass in the midline with no movement on tongue protrusion. Thyroid function, calcitonin and thyroid auto-antibodies were normal.

Ultrasound revealed a $4.0 \mathrm{~cm}$ hyper-echoic thyroid lesion arising from the isthmus. Fine needle aspiration cytology (FNAC) was reassuring with morphological features consistent with a benign colloid nodule and classified as Thy 2 , however due to the size of the mass the child underwent hemi-thyroidectomy which revealed nodular hyperplasia; ectopic intrathyroidal thymic tissue was also identified throughout the sample.

\section{Discussion}

Intra-thyroidal thymic tissue is an uncommon cause of neck swellings and has rarely been reported in the literature with published data from a small number of case reports [3,5]. The thymus is involved in adaptive immunity and T-cell function; it proliferates in the neonatal period and first decade of life and is vital for development of a mature immune system [6]. Embryologically, the thymus is derived from the endoderm of the third and fourth pharyngeal pouch during the 6th gestational week and as the thymo-pharyngeal duct elongates during the 7th week the thymus migrates inferiorly and medially towards the superior mediastinum $[4,6]$. Ectopic thyroid tissue can therefore be found anywhere from the angle of mouth to the superior mediastinum [5], meaning ectopic thymic tissue can easily be misinterpreted as a pathological neck lump, particularly in the paediatric population.

There are various reports of ectopic thymic tissue. Most commonly it is found as aberrant tissue within the neck, known as ectopic cervical thymic tissue [5]. There are only sporadic reports of in thyroidal thymic tissue, however it has previously been misdiagnosed as papillary thyroid cancer on ultrasound, similar to the case presented $[3,5]$. The exact epidemiology of intra-thyroidal thymic tissue remains unclear, however one study from Japan suggests that it is present in $1 \%$ of children [7]. Similar numbers were found in a study of perinatal thyroid glands [8]. With the increasing use and enhanced sensitivity of ultrasound, higher numbers of ectopic thymic tissue located within the thyroid gland may be detected and potentially misdiagnosed as malignancy, leading to diagnostic surgery, as in the two cases presented.

We present the cases of two children with intra-thyroidal thymic tissue who were referred to our paediatric head and neck tertiary referral service with thyroid masses. One child had a thyroid lesion that was radiologically suspicious for a papillary thyroid cancer with micro-calcifications and a mass that was taller than wide. Micro-calcifications are considered a highly suspicious feature on ultrasound, suggestive of papillary thyroid cancer and would result in a U5 grading on ultrasound according to the British Thyroid Association guidelines $[9,10]$. Hyperechoic foci within ectopic thymic tissue may be misinterpreted as micro-calcifications, which could mimic a malignant thyroid lesion. The other child had incidental thymic tissue identified throughout the thyroid gland in association with nodular hyperplasia.

The cases presented highlight the complexities of preoperative diagnosis of intra-thyroidal thymic tissue. However, with increasing usage of ultrasound imaging it is important to consider thymic remnant tissue as a differential diagnosis for thyroid nodules, especially as the imaging findings may mimic a malignant thyroid lesion. Unfortunately, due to the suspicious ultrasound features diagnostic thyroid surgery may still be inevitable.

\section{References}

1. M Niedziela (2006) Pathogenesis, diagnosis and management of thyroid nodules in children. Endocr Relat Cancer 13(2): 427-453.

2. Hogan AR, Zhuge Y, Perez EA, Koniaris LG, Lew JI, et al. (2009) Pediatric Thyroid Carcinoma: Incidence and Outcomes in 1753 Patients. J Surg Res 156(1): 167-172.

3. Park SH, Ryu CW, Kim GY, Shim KS (2014) Intrathyroidal thymic tissue mimicking a malignant thyroid nodule in a 4-year-old child. Ultrasonography 33(1): 71-73.

4. Prasad TRS, Chui CH, Ong CL, Meenakshi A (2006) Cervical ectopic thymus in an infant. Singapore Med J 2006 47(1): 68-70.

5. Huang Y, Zheng S, Xiao X (2013) Ectopic intrathyroidal thymus in children: Two case reports and review of the literature. Journal of paediatric surgery case reports 1 (11): 386-390.

6. Nasseri F, Eftekhari F (2010) Clinical and radiologic review of the normal and abnormal thymus: pearls and pitfalls. Radiographs 30(2): 413-428.

7. Fukushima T, Suzuki S, Ohira T, Shimura H, Midorikawa S, et al. (2015) Prevalence of ectopic intrathyroidal thymus in Japan: the Fukushima health management survey. Thyroid 25(5): 534-537.

8. Carpenter GR, Emery JL (1976) Inclusions in the human thyroid. J Anat 122(Pt 1): 77-89. 
9. Hoang JK, Lee WK, Lee M, Johnson D, Farrell S (2007) US Features of Thyroid Malignancy: Pearls and Pitfalls. Radiographics 27(3): 847-860.
10. Perros P, Colley S, Boelaert K, Evans C, Evans RM, et al. (2014) British thyroid association guidelines for the management of thyroid cancer. Clinical Endocrinology 81(Supp 1): 1-122.

\section{Your next submission with Juniper Publishers will reach you the below assets}

- Quality Editorial service

- Swift Peer Review

- Reprints availability

- E-prints Service

- Manuscript Podcast for convenient understanding

- Global attainment for your research

- Manuscript accessibility in different formats

( Pdf, E-pub, Full Text, Audio)

- Unceasing customer service

Track the below URL for one-step submission https://juniperpublishers.com/online-submission.php 